\title{
DIRECTIONALITY AND CONTEXT EFFECTS IN WORD TRANSLATION TASKS PERFORMED BY CONFERENCE INTERPRETERS
}

\author{
AGNIESZKA CHMIEL \\ Adam Mickiewicz University, Poznań \\ magnes@wa.amu.edu.pl
}

\begin{abstract}
Professional interpreters employed by international institutions usually work into their L1 from their L2, while freelance interpreters tend to work both into and from their L1. A study was devised to see if the long-term interpreting unidirectional practice (in the L2-L1 direction only), in contrast to bidirectional practice (in the L2-L1 and L1-L2 direction), influences the speed of lexical retrieval manifested through shorter translation latencies. Forty-eight professional conference interpreters produced oral translations of nouns presented in isolation, in high context constraint sentences and in low context constraint sentences. Contrary to predictions, unidirectional interpreters did not manifest directionality asymmetry and their L2-L1 translation latencies were not shorter than L1-L2 translation latencies. Surprisingly, the L2-L1 direction advantage was found in the group of bidirectional interpreters. The data suggest that the dominant directionality in interpreting practice has little impact on the strength of interlingual lexical links in the interpreter's mental lexicon or that other factors (such as language use, exposure and immersion) might offset any such impact. The study also revealed an expected context effect, which shows that interpreters use semantic constraint to anticipate sentence-final words.
\end{abstract}

KEYWORDS: conference interpreting; word translation; directionality; bidirectional interpreters; interpreting.

\section{Introduction $^{1}$}

Professional conference interpreters are bilinguals or multilinguals who provide specialized language services to facilitate communication between par-

\footnotetext{
${ }^{1}$ This research was funded by the Polish National Science Centre, grant no. DEC-2013/11/B/ HS6/ 01539 and by the Polish Ministry of Science and Higher Education, grant no. N N104 010637.
} 
ties not sharing the same language. Interpreters can be described by means of their working language profiles, including $\mathrm{A}, \mathrm{B}$ and $\mathrm{C}$ languages. According to the International Association of Conference Interpreters (AIIC 2014), the leading and the most prestigious professional organisation of conference interpreters, the working languages are classified into active languages (A and $B$, i.e. those into which interpreters work) and passive languages $(C$, i.e. those from which interpreters work). A language is "the interpreter's native language (or another language strictly equivalent to a native language), into which the interpreter works from all her or his other languages in both modes of interpretation, simultaneous and consecutive", B language is "a language other than the interpreter's native language, of which she or he has a perfect command and into which she or he works from one or more of her or his other languages". C language is the language "of which the interpreter has a complete understanding and from which she or he works" (AIIC 2014), a language the interpreter "fully understands and would most often speak to some extent, only not enough to work into that language" (DG Interpretation 2012).

Since many interpreters work on national markets where interpreting into $\mathrm{B}$ is a common practice, such different profiles of language use (unidirectionality - interpreting only into A language and bidirectionality - interpreting equally frequently into and from A language) might, with prolonged experience, have some bearing on the structure of the bilingual mental lexicon. According to the Revised Hierarchical Model (Kroll and Stewart 1994), word-to-word and word-to-concept links in the bilingual mental lexicon undergo changes in strength. It is assumed here that unidirectional interpreters will manifest a directionality effect, that is interpret words faster into their A language than into their B language, while bidirectional interpreters will perform symmetrically in both interpreting directions. Additionally, both groups will perform differently under semantically constrained and unconstrained contexts as a result of their professional practice. In an attempt to shed some light on the above issues, before presenting an experimental study I will review the issue of directionality in the conference interpreting practice and research and briefly discuss the Revised Hierarchical Model as a model of the bilingual's word production well suited to the discussion of lexical access in the context of conference interpreting.

This paper is a result of interdisciplinary research at the crossroads of interpreting studies and psycholinguistics. Thus, I should explain certain terminological discrepancies before proceeding further. As mentioned above, the interpreter's working languages are typically referred to as A, B and C. 
When applied to the characteristics of interpreters examined in the present study, A language corresponds to the interpreter's L1, B to L2 and C can be seen as roughly corresponding to $\mathrm{L} 3$. This paper draws upon psycholinguistic studies in its theoretical part and uses psycholinguistic methods in its experimental part, so I have decided to use the nomenclature consistent with psycholinguistics when referring to translation direction. Thus, L1-L2 versus L2-L1 labels will be used instead of A-to-B or B-to-A. Just as I refrain from using labels typical for interpreting studies (such as retour to denote L1-L2 interpreting), I also refrain from using more psycholinguistically motivated labels (such as forward and backward translation), although all of these labels will be mentioned in passing. L1-L2 and L2-L1 labels seem sufficiently neutral for the present paper.

Another discrepancy involves the nature of the translation task. Typically for translation and interpreting studies, translation is a term reserved to denote a written activity while interpreting denotes an oral activity. Similarly, translators provide written translations while interpreters provide oral renditions of the source language utterance. To add to the complexity, translation is also used as a hyperonym for written translation and oral translation, i.e. interpreting. This is somehow commensurate with the psycholinguistic tradition, in which tasks involving oral rendition of a stimulus word in the target language are referred to as word translation tasks. To reduce the terminological complexity, I will use the term "word translation task" to refer to a verbal response including a translation of the stimulus word presented visually. However, I will continue to use the terms conference interpreters and conference interpreting in the present paper.

\section{Directionality in interpreting}

\subsection{Professional practice}

Interpreting only into $\mathrm{L} 1$ is the mainstream practice in large international organisations, such as the United Nations, NATO, the European Commission and the European Parliament. Interpreters employed by such organisations usually interpret from their second and third languages into L1. Interpreting into L2 is commonly referred to as retour interpreting. Pavlović (2007: 81) lists other terms (such as inverse or reverse interpreting) and points to the negative connotations of names for L1-L2 interpreting or translating. She reviews a rather prescriptivist approach to directionality in Translation Studies 
which favours the L2-L1 direction. This is especially visible in the Western tradition shaped mainly by the Paris School (Seleskovitch and Lederer 1989). According to this approach, L1-L2 interpreting cannot be accepted as it results in lower quality. The underlying reasoning here is that production seems to be more important in interpreting than comprehension, thus the direction involving production in the interpreter's strongest language (i.e. into L1 language) is favoured. On the other hand, Eastern tradition represented by Denissenko (1989) and Chernov (1992) accepts L1-L2 interpreting by claiming that comprehension is key to its quality. Thus, L1-L2 interpreters are at an advantage since they interpret from their L1.

Interestingly, Gile (2005) demonstrates with the use of his Effort Model, that one can determine which interpreting direction is more favourable (i.e. requiring fewer processing resources thus leading to higher quality) depending on how one regards the difficulty of producing language in relation to the difficulty of comprehending it. If production is believed to be more cognitively demanding than comprehension, interpreting into $\mathrm{L} 1$ is preferable because it is easier to produce output in L1 than in L2. If comprehension is supposed to consume more cognitive resources than production, the reverse would be true. There are, however, other factors that come into play (such as poor sound conditions which favour interpreting into L2, as it would be easier to comprehend one's L1 under difficult conditions (see Gile 2005 for a review). Language pair specificity is another such factor. For example, in the case of interpreting between Polish and English, interpreting into Polish, which is a highly inflectional language, may be more prone to inflectional errors due to the need to self-monitor suffixes in production; on the other hand, interpreting into English, which is more constrained than Polish in word order, may be prone to syntactic errors as it requires more sentence-level restructuring. I will come back to the importance of comprehension and production in interpreting later when reviewing empirical studies on directionality in interpreting.

Regardless of the theoretical views on directionality and mainstream practices in large organisations, L1-L2 interpreting (especially when L2 is English) seems to be a regular practice in countries with languages with limited diffusion (Donovan 2002: 2; Pavlović 2007), including Central and Eastern European countries (Szabari 2002: 13). This is because there are rarely many English native speakers with Croatian, Polish, Finnish or Danish available and because installing two separate booths and hiring four unidirectional interpreters instead of two bidirectional interpreters for a bilingual event would not be economically sound. A survey conducted by Pavlović 
(2007: 87) on Croatian professionals working both as interpreters and as translators found that most of them (57 out of 59 respondents) interpret from L1 into L2 and that as many as $73 \%$ work from L1 more than into L1. Interestingly, as regards directionality preferences, one third of the respondents prefer working into L1, one third into L2 and one third has no preference. Other studies confirm that interpreters work equally much into and from their active language in Hungary (Szabari 2000, as quoted in Szabari 2002: 13) and other Central European countries (Katschinka 2002, as quoted in Szabari 2002: 13). The US and Korean markets are similar in this respect. 68 percent of professional interpreters from the US market surveyed by Nicodemus and Emmorey (2013: 628) reported direction preference, the majority of them (72.5 percent) pointing to the L2-L1 direction. This was in line with their self-reported proficiency ratings (higher in interpreting into L1 than into L2). Lim (2005) surveyed professional interpreters working in Korea and associated with AIIC to ask about the practice of retour and the professionals' sentiments toward it. $33 \%$ of Korean interpreters and $18 \%$ of AIIC interpreters reported that half of their work was in the retour mode (L1-L2), showing again that the local market practice is remote from the prescriptivist view of Western scholars and trainers.

\subsection{Empirical studies}

A number of empirical studies focused on the issue of directionality. I will first review typically interpreting studies that used either simultaneous or consecutive interpreting as an experimental task and then psycholinguistic studies employing a word translation task.

As mentioned above, the ease of interpreting as a function of directionality is closely related to the ease of comprehension and production in the interpreter's L1 and L2. L2-L1 interpreting is advantageous because production in L1 is less cognitively demanding than in L2. And vice versa, L1-L2 interpreting might be more successful in a sense that it is easier to comprehend one's L1, especially under difficult conditions. Gran and Fabbro (1988: 40) found that interpreting into L1 was less demanding and tiring to their participants than interpreting into L2 because language production control was more efficient and more automatic in L1. Chang (2005) conducted a propositional analysis of semantic context and found better quality in interpreting into L1 as compared to interpreting into L2. The author explained this result through the professionals' awareness of L2 language production 
deficits. When interpreting into L2, professionals were reluctant to express minor propositions when they suspected the expression quality would not be up to a par. The effect of the delivery rate was similar in both interpreting directions while the effect of language proficiency resulted in a more natural output in L1 (more idioms and set phrases) than in L2 (Chang 2005: 124). Chang concluded that although interpreters were committed to achieving the best possible quality of L1-L2 interpreting, "occasionally the disadvantage of producing in one's B language [L2] still overpowered the advantage of listening to one's A language [L1]" (Chang 2005: 124). Donovan (2005) reported more production problems (including unclear and awkward expressions), more numerous and prolonged breakdowns in coherence and reasoning in L1-L2 interpreting as compared to interpreting into L1. The beneficial effect of preparation before the interpreting assignment was reported as being more pronounced in L1-L2 than in L2-L1 interpreting. Donovan concluded that although "the number of major deviations from the original and of instances of loss of coherence or breakdown is significantly larger for work into L2", "experienced interpreters seem to develop strategies to avoid this (...) and remain more in control" (Donovan 2005: 44). Mead (2005) examined trainees and found a higher incidence of pauses in L1-L2 than L2L1 interpreting. He thus claimed that the latter was more fluent than the former. All of these studies seem to point to the superiority of L2-L1 interpreting due to the ease of production in one's L1. On the other hand, Tommola and Helevä (1998) found an opposite directionality effect only in linguistically complex, and not simple texts. Trainee interpreters examined in their study managed L1-L2 interpreting of difficult texts better than L2-L1 interpreting. Kurz and Färber (2003) demonstrated that trainees anticipated more in L1-L2 interpreting, which positively correlated with better quality.

A closer look at strategies employed in both interpreting directions can also be beneficial since interpreting is a highly strategic activity (Gile 2015). Bartłomiejczyk (2006) found some differences between interpreting from and into L1 in terms of strategies used by interpreting trainees elicited via retrospective interviews. Students used inferencing (constructing meaning on the basis of context), parallel reformulation (inventing probable sentence endings due to comprehension or processing problems) and transcoding (word-for-word interpreting and retention of source sentence structure) in L2-L1 interpreting more often than in L1-L2 interpreting. The first two strategies show problems with comprehension, which could be avoided in L1-L2 interpreting, while the last strategy manifests production problems, which could be even worse in L1-L2 interpreting. These results do not sug- 
gest any preferred direction due to employed strategies (which could lead to better quality or problem management). In a study by Gumul (2006) trainees used more instances of explicitation (especially by means of adding connectives, specification of meaning and metaphor disambiguation) in L1L2 interpreting as compared to L2-L1 interpreting.

To conclude, the studies showing a directionality effect in interpreting (superior performance in L2-L1 direction) outnumber those showing the opposite pattern. In terms of strategies, interpreters seem to use both comprehension- and production-oriented strategies and are more successful in applying them in their L1. However, many of those studies involved interpreting trainees and we do not know whether and how these results are generalizable to the population of professional conference interpreters, especially as numerous studies have found processing advantages of interpreters over trainees (e.g. Sunnari 1996; Riccardi 1998; Padilla et al. 1995; Jörg 1997).

As opposed to experiments using conference interpreting as a task, in studies involving a word translation task it is possible to isolate processes involved in word comprehension and retrieval. It turns out that the directionality effect is modulated by language proficiency. Christoffels found no directionality effect in an isolated word translation task performed by noninterpreting bilinguals (Christoffels et al. 2003: 206), but there was a language dominance effect in the picture naming task, i.e. bilinguals retrieved picture names faster in their L1 than in their L2. The authors explained the lack of linguistic asymmetry in word translation by means of the high L2 proficiency. However, one has to bear in mind that the participants of the study were not conference interpreters, unlike in my study reported below. In a similar study Christoffels et al. (2006) compared professional interpreters, non-interpreting bilingual students and teachers (proficient speakers of L2). Interpreters were faster than bilinguals in a picture naming task in L2, but not in L1. The directionality effect in a word translation task was reported in bilinguals only, not in interpreters or language teachers. The authors concluded that fast lexical retrieval was key to, but not unique for, conference interpreting (since participants with experience in other activities involving proficient language use, such as language teaching, showed a similar pattern of results). In a similar vein, de Bot (2000) conducted a word translation and verification study to reveal potential directionality effects in three groups of bilinguals (intermediate, advanced and proficient). He found asymmetry in the first two groups: less proficient bilinguals translated faster into L1 than into L2. The proficient group did not manifest any directionality effect. In a follow-up experiment the participants had to verify if word translations were correct. 
There was no difference between word translation and verification task for the intermediate group while the latencies for translation were longer than for verification in the advanced and proficient bilingual groups. Since error rates were lower in the verification task as compared to translation, de Bot interpreted them as showing that the least proficient speakers knew the tested words but not well enough to produce them quickly in L2 (de Bot 2000: 84). It seems that proficiency influences word translation directionality and the asymmetry diminishes with increasing proficiency.

De Bot mentioned translation strategies as an important factor, alongside word retrievability from the mental lexicon, influencing the interpreting process. He claimed that "even though it takes more time to find the right words, the advantage of a better and deeper understanding of the incoming speech more than compensates for this" (de Bot 2000: 85), which may be a good argument in favour of L1-L2 interpreting. This view is shared by Rejšková (2002), who claimed that advantages of L1-L2 interpreting included better comprehension and anticipation and an easier choice of the right interpreting technique (such as summary, prioritising, omission): "when the choice of your technique is successful - there is more chance your production will contain fewer grammatical errors, false starts etc. provided linguistic proficiency of B [L2] is up to the task" (Rejšková 2002: 32).

\section{Directionality in the interpreter's mental lexicon}

I will now discuss directionality in interpreting from a psycholinguistic perspective by looking at the model of word production in the bilingual mental lexicon. According to the Revised Hierarchical Model (Kroll and Stewart 1994), meaning is stored in the mind on the language-free conceptual level while words are maintained on the language specific lexical level with separate stores for each known language. The links between words and concepts, or word-to-concept mappings vary in strength depending on language proficiency and use. In less proficient speakers of L2, L1-L2 translation is mediated via the conceptual level because the links between words, or lexical links are weak whereas L2-L1 translation occurs on the lexical level because L2-L1 lexical links are strong. Thus, the latter type of translation (frequently referred to as backward translation in psycholinguistic literature) is faster than L1-L2 (forward) translation. The translation assymetry shown in numerous studies (Kroll and Stewart 1994; Sholl et al. 1995) supporting the model is said to decrease with increased L2 proficiency 
(Kroll et al. 2002; Kroll et al. 2010). This is consistent with the studies involving interpreters or interpreting trainees manifesting no directionality effect in word translation studies reviewed in Section 2.2 above.

The RHM posits that there is language non-selectivity and parallel activation of both languages in linguistic processing (Kroll et al. 2010). Following that, I assume that the specific use of languages by conference interpreters influences the organization of the bilingual mental lexicon and lexical processing, i.e. the strength of word-to-concept links and cross-language lexical links in the mental lexicon (Shreve and Diamond 1997; Setton 1999). As de Groot and Christoffels (2006) claim:

\begin{abstract}
the associations themselves are formed just as all associations are formed, that is, by contiguity of the elements in the environment (and possibly by mental contiguity, that is, by the co-occurrence of words in thought). In other words, the representations of the words belonging to one particular language become strongly interconnected in bilingual memory because they co-occur (in different combinations) in actual language use and are encountered as such by the language user.
\end{abstract}

Interpreters may use a twofold strategy in their practice: a meaning-based one, which focuses on rendering the message without much consideration of the similarity of form, and a form-based, or word-for-word one, according to which the target text form resembles the source text form. Although the precedence of the meaning-based strategy over the word-for-word strategy is generally acknowledged in Translation Studies (Seleskovitch 1978), direct word-to-word mappings may be useful in interpreting when retrieving certain types of lexical items, such as monoreferential terms (terminological equivalents), established corresponding terms, idioms and pat phrases (cf. Seleskovitch et al. 1995; Setton 1999). Interpreters are said to alternate between meaning-based and form-based strategies (see van Dam 2001 for an extensive review). However, even the application of the form-based strategy should not and does not preclude semantic processing in this type of lexical access, especially as a certain degree of conceptual processing in lexical tasks has been shown to occur even in less fluent bilinguals with weak wordto-concept mappings that favour lexical level processing only (Duyck and Brysbaert 2008; de Groot and Poot 1997; de Groot et al. 1994). In general, I assume that due to the special type of bilingual processing that is involved in conference interpreting interpreters develop stronger word-to-concept and word-to-word mappings which result in shorter translation latencies as 
compared to non-interpreters (Chmiel, in preparation). Additionally, in line with the RHM approach, direction asymmetry (faster L2-L1 translation) should disappear in interpreters as fluent and proficient L2 users. However, since directionality in the interpreters' professional activity might have some bearing on the strength of lexical links in their mental lexicon, translation asymmetry might again arise. Unidirectional and bidirectional interpreters are especially interesting groups to consider in this context. It is hypothesized here that unidirectional interpreters (working predominantly from their L2 and L3 languages into their L1) will show translation asymmetry as opposed to bidirectional interpreters (working more or less equally frequently from and into their L1). To be more precise, I predict that unidirectional interpreters will have shorter translation latencies in interpreting words from L2 into L1 than when working from L1 into L2. Bidirectional interpreters, as proficient bilinguals exposed to equal amounts of work into both directions, will show a translation symmetry typical of high fluency L2 speakers (as shown by Kroll et al. 2002).

\section{Semantic context effects in word processing}

We need to remember that many studies reviewed above focused on translation of single isolated words rather than words in context constraints. In the present study I also manipulated context and included some target words in sentences with or without semantically constraining context. Context has been shown to influence word processing (Altarriba et al. 1996; van Hell 2005). Words in a semantically constraining context are recognised faster than in a neutral one.

Semantic constraint effects have been reported both in studies involving word recognition tasks in L1 (Schwartz and Kroll 2006) and in studies with L1-L2 and L2-L1 word translation tasks (van Hell and de Groot 2008). In the latter study, translation of words embedded in a high context constraint was always faster than translation of words in a low context constraint and in isolation. As regards the comparison of the low context and no context condition, there was either no difference (in L1-L2 direction) or isolated words were translated faster than low context condition words (in L2-L1 direction). However, these studies involved regular bilinguals without interpreting experience.

The effect of semantic constraint was also reported in a study where context was created not by a sentence but by a presence of a semantically related 
picture (Heij et al. 1996). The pictures facilitated word translation in both directions, which led the authors to conclude that both L1-L2 and L2-L1 were conceptually mediated and that concept activation was easier in L1.

Eye-tracking studies have also provided interesting evidence regarding sentence context constraints. Van Assche et al. (2011) and Titone et al. (2011) observed semantic constraint effect in early and late reading measures and confirmed that L1 was still activated in reading sentences in L2 although this cross-linguistic activation was attenuated in high context constraint as compared to low context constraint.

Morris (2006) claims that sentence context effects might be partially explained by anticipation due to predictability and partially by intralexical priming and activation spreading to semantically related words. In general, research conducted so far seems to suggest that semantic constraint strongly influences word processing but the exact nature of this facilitation remains unknown.

\section{The experiment}

In the present study I expect the facilitation effect of the high context constraint for both groups of participants. Interpreters will use the semantically constraining context to activate meanings and retrieve translation equivalents faster both in L1-L2 and L2-L1 direction. It is further hypothesized that high constraint context will facilitate word production in L1-L2 more than in L2-L1 for bidirectional interpreters because they will benefit from L1 comprehension advantage. However, I expect to see no context by direction interaction in unidirectional interpreters, as L1 comprehension advantage will be offset by long-term interpreting practice in L2-L1 direction.

\subsection{Method}

The study design was 2 (group: unidirectional interpreters, bidirectional interpreters) by 2 (direction: English-Polish, Polish-English) by 3 (context: high context, low context, no context) with group as a between-groups factor, direction and context as within-subject factors and response time as a dependent variable. The task involved interpreting of words presented visually either in a sentence-final position or in isolation. 


\subsection{Participants}

The study involved 24 professional interpreters working for the European Commission and the European Parliament comprising the group of unidirectional interpreters (i.e. working predominantly into A) and 24 professional conference interpreters working free-lance on the Polish market comprising the group of bidirectional interpreters (i.e. working both into and from A). Table 1 presents characteristics of both groups.

Table 1. Experimental groups.

\begin{tabular}{lcc}
\hline & $\begin{array}{c}\text { Unidirectional interpreters } \\
(\mathrm{N}=24)\end{array}$ & $\begin{array}{c}\text { Bidirectional interpreters } \\
(\mathrm{N}=24)\end{array}$ \\
\hline Mean age & 38 years & 38 years \\
Mean professional & $(\mathrm{SD}=5.49 ;$ range $=31-48)$ & $(\mathrm{SD}=8.37$ range $=28-60)$ \\
experience & 10 years & 13 years \\
$\begin{array}{c}\text { Percentage of total work } \\
\text { time spent interpreting } \\
\text { into B language } \\
\text { (directionality) }\end{array}$ & $(\mathrm{SD}=5.28 ;$ range $=3-24)$ & $(\mathrm{SD}=8.12 ;$ range $=4-35)$ \\
\hline
\end{tabular}

The participants were asked to estimate how much they interpret into their B language in a pre-study questionnaire. The groups did not differ in age and professional experience $(p>.05)$ but they differed significantly in directionality $(\mathrm{p}<.001)$.

The group of unidirectional interpreters included: 17 full-time employees and 7 free-lancers; 13 males and 11 females. They have worked for the EU institutions for the average of 5 years, which was shorter than their mean professional experience in conference interpreting (10 years). The difference was due to the fact that Poland joined the EU (and Polish became one of its official languages) only in 2004. All the unidirectional interpreters worked for the Polish booth, i.e. Polish was their A language, English was their B language and all but two of them had one or two $\mathrm{C}$ languages (such as French, German, Greek, Czech, Swedish, Spanish and Italian).

The group of bidirectional interpreters included 11 males and 13 females. Conference interpreting was the primary source of income for $37 \%$ of them, 
$79 \%$ of them worked also as translators. The average number of conference days per month in the last three years of their career was estimated at 6.39 $(\mathrm{SD}=4.81$, range $=1-15)$. Their A language was Polish, their B language English and 11 of them had either one or two C languages (such as Russian, French, German, Italian, Spanish and Swedish).

\subsection{Stimuli}

The stimuli were selected from a study by Kujałowicz et al. (2008). They included 39 Polish and 39 English nouns matched for frequency and length. Each word occurred in three conditions: high context constraint (HC), low context constraint (LC) and no context (NC). All the words were judged as concrete (6 or higher on a 7-point Likert scale) in a pre-test conducted by Kujałowicz et al. (2008) among 50 proficient speakers of English as L2 (students of English). An additional norming study involved 50 participants from the same population to determine high and low constraint sentences, which was modelled after van Hell (2005). Kujałowicz et al. (2008) created a high context constraint and a low context constraint sentence for each stimulus. The sentences were presented without the final stimulus word to the participants, who were asked to complete the sentences in a logical and plausible way with a noun. If a sentence was completed with the desired stimulus word by at least 80 percent of the respondents for Polish and at least 70 percent for English, the sentence was selected as a high context constraint sentence for the stimulus. Similarly, if a sentence was completed with the desired stimulus word by not more than 20 percent of respondents for Polish and not more than 30 percent for English, the sentence was selected as a low context constraint sentence for the stimulus. This sentence norming test was repeated twice by Kujałowicz et al. (2008) since not all initially proposed sentences received the desired completion scores. Each participant completed only one (either HC or LC) sentence for a given stimulus and the contexts were randomised in the norming study.

As a result, $39 \mathrm{HC}$ sentences and $39 \mathrm{LC}$ sentences were generated for 39 Polish stimuli and $39 \mathrm{HC}$ sentences and $39 \mathrm{LC}$ sentences were generated for 39 English stimuli. Table 2 presents examples of stimulus sentences ${ }^{2}$.

\footnotetext{
${ }^{2}$ The full set of stimulus sentences can be obtained by contacting the author.
} 
Table 2. Sample stimulus sentences with target words in the sentence-final position.

\begin{tabular}{lc}
\hline High context constraint sentence & Low context constraint sentence \\
\hline $\begin{array}{l}\text { Fold the letter and put it into } \\
\text { an ENVELOPE. }\end{array}$ & $\begin{array}{c}\text { He made a few notes on the back } \\
\text { of the ENVELOPE. }\end{array}$ \\
$\begin{array}{l}\text { The girl was trying to reach the book } \\
\text { on the top SHELF. }\end{array}$ & $\begin{array}{c}\text { She was drawing a vase of flowers } \\
\text { on the SHELF. }\end{array}$ \\
$\begin{array}{l}\text { She loves pepperoni pizza } \\
\text { with double CHEESE. }\end{array}$ & $\begin{array}{c}\text { Stir in broccoli, tomatoes } \\
\text { and CHEESE. }\end{array}$ \\
\end{tabular}

In the no context condition, words were presented without any sentence context. Three sets of experimental words and sentences were created for the experiment for each language. Each set included 13 words in $\mathrm{HC}$ condition, 13 words in LC condition and 13 words in NC condition. I randomised the conditions across sets (A, B, C). Each set included the sentence part with randomised $\mathrm{HC}$ and $\mathrm{LC}$ conditions and a word part with $\mathrm{NC}$ condition.

\subsection{Procedure}

The experiment was run on a laptop computer in a normally lit room. I designed the study in E-Prime 2.0 software and measured the verbal reaction times (how fast the participants spoke word translations into the microphone) with the Serial Response Box. Half of the participants started the experiment with the English part (translation into Polish) and the other half started with the Polish part (translation into English). I gave both verbal and written instructions in the respective source language. Each participant was presented with only one set (A, B or C) for each language. A short practice session with 5 sentences and stimuli preceded each experimental session for each language. In each trial, the participants first saw a fixation mark displayed centrally in black on a white screen for $500 \mathrm{~ms}$ and then a HC or LC sentence without the final word. The participants were instructed to read it carefully and press the space bar immediately after having read the sentence. They saw the fixation mark again for $500 \mathrm{~ms}$, which was followed by a stimulus word displayed on the screen for $10,000 \mathrm{~ms}$ or until the participants gave a verbal response. They were instructed to translate the word as quickly and as accurately as possible into the other language and the word disappeared when the voice key recorded the verbal response. The experimenter marked both cor- 
rect and incorrect responses. Another fixation mark commenced the next trial. The sentence part of the experiment was followed by a short pen-andpaper sentence recognition task. The participants read a list of 7 sentences and were asked to tick sentences that they saw in the experiment (the number of the actual experimental sentences in each recognition task ranged from 2 to 5). This was to confirm that the participants really read the sentences and processed their meaning before moving to word translation. This was followed by the word part of the experiment. The participants saw the fixation mark again for $500 \mathrm{~ms}$ and then a stimulus word for the maximum of 10,000 msec. Again, they were instructed to translate the word as quickly and as accurately as possible into the other language and the word disappeared when the verbal response was recorded by the voice key. A blank screen appeared for $1000 \mathrm{~ms}$ and a subsequent trial was commenced by another fixation mark. After the sentence part and the word part in one language the participants followed the same procedure in the other language.

\subsection{Data trimming}

First, the results of the sentence recognition study had to be taken into account. It turned out that there were no scores lower than 5 correct answers out of 7 sentences. In the group of unidirectional interpreters, the recognition score was $100 \%$ for Polish sentences and $98 \%$ for English sentences. In the group of bidirectional interpreters, the recognition score was $98 \%$ for Polish sentences and $99 \%$ for English sentences. Thus, I excluded no data on the grounds of the insufficient sentence recognition scores. Only correct answers, i.e. the actual stimulus words produced as translations, could be considered so the next step in data trimming consisted in excluding omissions (i.e. when the maximum stimulus display time elapsed before any reply was given) and errors (which could be either correct translations but not the actual stimulus words, wrong translations or other vocalisations, such as gap fillers, smacking sounds, etc., which triggered the voice key before the answer was given). Since the English and Polish stimuli were matched for frequency and since frequency has been proven to affect lexical processing, I had to exclude from analysis those correct translations that did not match my normalized stimuli. Omissions and errors constituted $13 \%$ of the unidirectional professionals' responses and $8 \%$ of the bidirectional professionals' responses. No separate error rate analysis was performed because no distinction was made between the above mentioned causes for errors when recording the da- 
ta. In total, $11 \%$ of the data were trimmed due to omissions and errors. The outliers were eliminated in the following way: all observations with reaction times below $250 \mathrm{~ms}$ and above three times the interquantile range were eliminated. As a result further $5 \%$ of the data were eliminated as outliers.

\subsection{Data analysis}

Although the initial design was planned with ANOVA-type analysis in mind, I analyzed the actual results with the linear mixed-effects model (LME) using the lme4 library (Bates 2007) in the statistics software R (R Development Core Team 2009). In a regular ANOVA, participants are typically used as a random factor since one individual can generally react faster to certain stimuli than other (such analyses result in the $F_{1}$ statistic). Additionally, in some studies experimental results are also analysed assuming the randomness of the linguistic stimuli (the $\mathrm{F}_{2}$ statistic), but there is no good way to combine the two in a single ANOVA analysis. LME models make it possible to incorporate both random factors (participants and items) into the analysis and handle categorical data better than analyses of variance (Baayen et al. 2008).

Following Baayen (2008) and partially following Barr et al. (2013) I first created the maximal LME model including two random effects (participants and items) and all potential factors and two-way and three-way interactions between them (group, context, direction). I compared the most complex model to a progressively less complex model to identify the best model including only the predictors that significantly improved the model fit. I used Satterthwaite approximations to degrees of freedom to obtain $\mathrm{p}$ values for $\mathrm{t}-$ tests included in the model.

\subsection{Results}

The final LME model included (apart from participants and items as random effects) the following predictors: direction, context and a two-way interaction between direction and context.

Table 3 and Figure 1 present mean results for all experimental conditions for both groups. The mean reaction time for unidirectional interpreters was $902 \mathrm{~ms}$ and the mean reaction time for bidirectional interpreters was $880 \mathrm{~ms}$. There was no main effect of group (the difference of $22 \mathrm{~ms}$ was not statistic- 
Table 3. Mean results (in ms), standard deviations (SD) and ranges by condition.

\begin{tabular}{lcc}
\hline \multicolumn{2}{c}{ Group } & D2-L1 \\
\hline \multicolumn{3}{c}{ L1-L2 } \\
\hline Unidirectional interpreters \\
\hline HC & 749 & 736 \\
& $(\mathrm{SD}=291 ;$ range $=266-1827)$ & $(\mathrm{SD}=327 ;$ range $=269-1865)$ \\
LC & 992 & 1015 \\
& $(\mathrm{SD}=249 ;$ range $=435-1884)$ & $(\mathrm{SD}=291 ;$ range $=495-1825)$ \\
$\mathrm{NC}$ & 941 & 990 \\
& $(\mathrm{SD}=291 ;$ range $=539-1883)$ & $(\mathrm{SD}=291 ;$ range $=576-1858)$ \\
\hline Bidirectional interpreters $\quad$ & 723 \\
\hline HC & $(\mathrm{SD}=277 ;$ range $=253-1823)$ & $(\mathrm{SD}=264 ;$ range $=314-1767)$ \\
& 945 & 993 \\
LC & $(\mathrm{SD}=243 ;$ range $=300-1815)$ & $(\mathrm{SD}=259 ;$ range $=482-1870)$ \\
& 910 & 969 \\
NC & $(\mathrm{SD}=232 ;$ range $=352-1669)$ & $(\mathrm{SD}=234 ;$ range $=422-1878)$ \\
\end{tabular}

ally significant, $\mathrm{t}=0.893, \mathrm{p}>.05$ ). There was a significant main effect of direction, in that reaction times were $25 \mathrm{~ms}$ longer in L1-L2 translation $(\mathrm{M}=$ $902 \mathrm{~ms})$ than in $\mathrm{L} 2-\mathrm{L} 1$ translation $(\mathrm{M}=878 \mathrm{~ms})(\mathrm{t}=2.824, \mathrm{p}=.004)$. There was a context effect, with a statistically significant difference between $\mathrm{HC}$ $(\mathrm{M}=738 \mathrm{~ms})$ and $\mathrm{LC}(\mathrm{M}=986 \mathrm{~ms})$ : the words in high context constraint sentences were translated $248 \mathrm{~ms}$ faster than the words in low context constraint sentences $(\mathrm{t}=25.162, \mathrm{p}<.001)$. The difference between LC and $\mathrm{NC}(\mathrm{M}=953 \mathrm{~ms})$ also turned out to be significant: words presented without any context were translated $33 \mathrm{~ms}$ faster than words in low context constraint sentences $(\mathrm{t}=-3.371, \mathrm{p}<.001)$. The interaction between direction and context was also statistically significant, in that the high context facilitation varied as a function of direction $(\mathrm{t}=2.556, \mathrm{p}=.01)$. No other interactions turned out to significantly improve the fit of the model.

To examine planned comparisons for directionality effects for unidirectional and bidirectional interpreters separately, I created two more LME models following the same procedure. The final LME model for the group of unidirectional interpreters included participants and items as random factors and only one predictor of context because neither the factor of direction nor the interaction between direction and context turned out to 


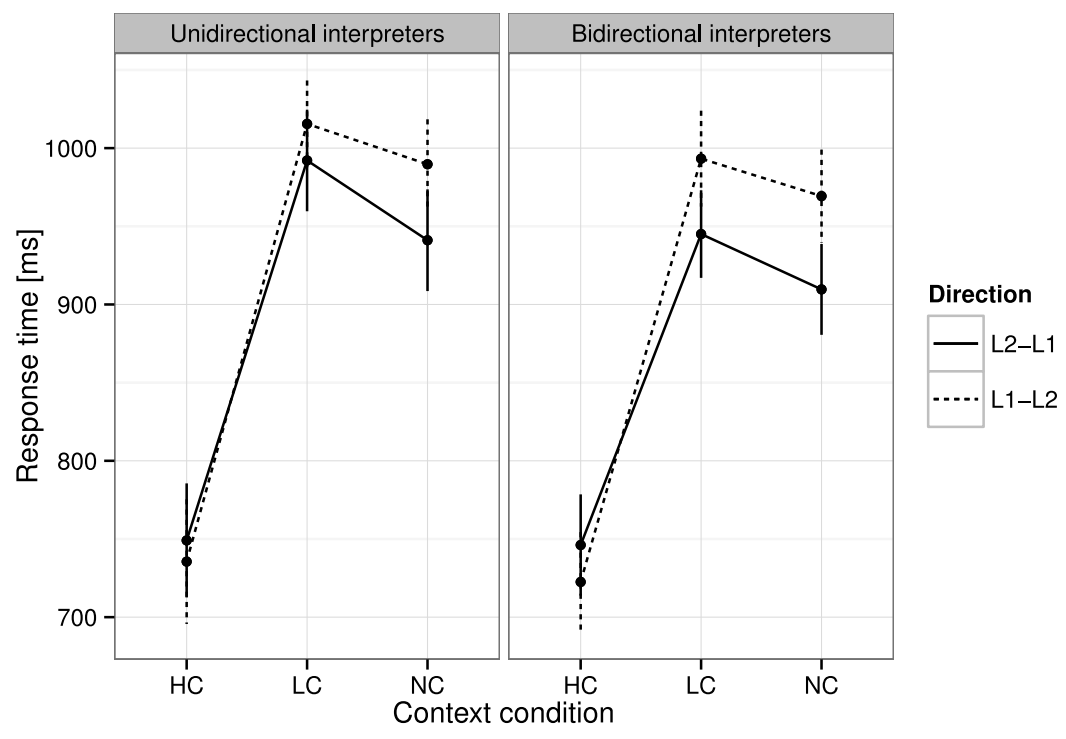

Figure 1. Word translation in context constraints.

be significant. The unidirectional interpreters interpreted words embedded in low context constraint $(\mathrm{M}=1007 \mathrm{~ms}) 267 \mathrm{~ms}$ slower than words in high context constraint $(\mathrm{M}=740 \mathrm{~ms})(\mathrm{t}=17.856, \mathrm{p}<.001)$ and $43 \mathrm{~ms}$ slower than words in isolation $(\mathrm{M}=964 \mathrm{~ms})(\mathrm{t}=2.647, \mathrm{p}=.008)$. The final LME model for the group of bidirectional interpreters included participants and items as random factors and direction, context and an interaction of direction and context as fixed effects. Bidirectional interpreters translated words in L1-L2 direction $(\mathrm{M}=891 \mathrm{~ms}) 26 \mathrm{~ms}$ slower than in $\mathrm{L} 2-\mathrm{L} 1$ direction $(\mathrm{M}=865 \mathrm{~ms})$ $(\mathrm{t}=2.278, \mathrm{p}=.023)$. Context also modulated their response times in that high context constraint $(\mathrm{M}=734 \mathrm{~ms})$ reduced reaction times by $232 \mathrm{~ms}$ as compared to low context constraint $(\mathrm{M}=966 \mathrm{~ms})(\mathrm{t}=17.292, \mathrm{p}<.001)$. Additionally, in a two-way interaction, context facilitation varied as a function of direction $(\mathrm{t}=2.361, \mathrm{p}=.018)$. In high context constraint, $\mathrm{L} 1-\mathrm{L} 2$ translation was faster than L2-L1 translation, while in low context constrain L1-L2 translation was slower than L2-L1 translation. 


\subsection{Discussion}

The analysis revealed no group effect. This was expected as both groups of participants work as professional conference interpreters and they did not differ significantly in their professional experience. Across all participants and conditions, there was a significant directionality effect. Interpreters provided L2-L1 translations faster than L1-L2 translations. This outcome seems to support the proponents of interpreting into one's native language only (Seleskovitch and Lederer 1989), corroborates the results of Gran and Fabbro (1988), but is at a variance with the results obtained by Christoffels et al. (2006). The language asymmetry effect resembles that characteristic of less proficient non-interpreting bilinguals (Christoffels et al. 2003). However, since translation latencies are faster for interpreters as compared to noninterpreting bilinguals (Chmiel, in preparation), it seems more probable that the asymmetry should be explained by factors other than language proficiency. I will return to this issue when discussing the directionality effect separately for both groups of participants. The study also revealed a significant context effect, with high context constraint shortening translation latencies for both groups. This was expected and corroborates the findings of other studies (van Hell 2005; Altarriba et al. 1996; van Hell and de Groot 2008). When reading high context constraint sentences, the participants incrementally analysed them semantically, anticipated the sentence-final word, preactivated it and, as a result, provided the translation equivalent faster. It is also interesting to see that isolated words were translated faster than words in low context constraint sentences. I may explain that in the following way: when processing the low context constraint sentences, the interpreters again tried to anticipate the sentence-final word. However, since the context did not provide them with any clues, they pre-activated many potential candidates and when the word was finally presented they had to significantly raise the activation level of the appropriate word and inhibit the remaining ones. In contrast, when presented with an isolated word in the no context condition the interpreters simply activated the most natural translation equivalent. There were much fewer competitors to inhibit and thus the reaction times were shorter. Alternatively, or additionally, this might have been a manifestation of direct retrieval of lexemes and the lack of conceptual processing. ${ }^{3}$

Following the creation of separate models for both groups, it turned out that the directionality effect was visible only for the scores of the bidirec-

\footnotetext{
${ }^{3}$ I thank the anonymous reviewer for that suggestion.
} 
tional interpreters. This is contrary to my assumptions, as I expected a directionality asymmetry in unidirectional interpreters only due to their predominant experience of interpreting into their L1 only. As mentioned earlier, it might appear that unidirectional interpreters manifesting no directionality effect resemble the pattern revealed for proficient L2 users while bidirectional interpreters manifesting an L2-L1 directionality advantage resemble less proficient L2 users (Kroll et al. 2010; Sunderman and Kroll 2006). However, such explanation of these results seems unlikely since both groups are highly proficient bilinguals and professional conference interpreters with no difference in experience and my study has not revealed any group effect in their reaction times. I suggest that the nature of interpreting practice (unidirectional vs. bidirectional interpreting) is not the only factor influencing the strength of interlingual links in the mental lexicon. Other factors may include language exposure and language use. The unidirectional participants had lived in Brussels for at least five years prior to the study, they use both English and French (if known) in their professional environment outside the interpreting booth on a daily basis and they are immersed in a French-speaking environment outside their place of work (but most of them use Polish at home). In contrast, the bidirectional participants live in Poland and use their L1 predominantly in both professional and non-professional settings (except when they interpret in the booth - then they use Polish for the average of $49 \%$ of the booth time, see Table 1). I may thus assume in line with Linck et al. (2009) that the L2 immersion environment inhibits L1, which is why the unilingual interpreters do not manifest the L2-L1 directionality advantage.

Separate models for both groups revealed an expected context effect with high context as a facilitating factor, which I explained above. However, I can report a significant interaction between context and direction only for the group of bidirectional interpreters. This is exactly the pattern I have predicted. It is interesting to see that in high context constrained sentences those interpreters produced word translations faster in the L1-L2 condition than in the L2-L1 condition. The situation was reversed in low context and no context condition - L2-L1 translations were faster than L1-L2 translations. This is not surprising if considered in the context of comprehension and production in L1 and L2. In the high context constraint interpreters show an L1 comprehension advantage, that is they anticipate the sentence-final word more efficiently in L1 as compared to L2. As a result, their translations are faster in the L1-L2 direction. In the low context constraint anticipation is less successful so there is no L1 comprehension advantage. This explanation is also in line with Heij et al. (1996), who claimed that in L1-L2 it is easy to 
activate a concept (what I called an L1 comprehension advantage) and difficult to retrieve an L2 equivalent while in L2-L1 translation concept activation is more difficult (no L2 comprehension advantage) but L1 equivalent retrieval is easier. My study has revealed that the bidirectional interpreters show a regular L2-L1 advantage in the production of translation equivalents. As predicted, I cannot report a similar context by direction interaction for the group of unidirectional interpreters. I speculate that it might be because L1 comprehension advantage is attenuated by long-term interpreting practice in L2-L1 direction. Since these interpreters work predominantly from L2, it might be that their anticipation skill in L2 has improved to match that in L1.

In general, my findings do not confirm my assumptions regarding the directionality effect in word translation performed by unidirectional and bidirectional interpreters. Contrary to expectations, I found directionality effects only in the group of bidirectional interpreters and not in the group of unidirectional interpreters. I explain these results by claiming that the nature of interpreting practice (the predominant direction the interpreters work in) is not the sole factor influencing the strength and the asymmetry of lexical and conceptual links in the mental lexicon. It seems that such factors and language use, exposure and immersion play a far more important role. What is more, I have used fairly frequent concrete nouns as the critical words in the study. However, a study by van Hell and de Groot (2008) has shown an L2L1 direction advantage for highly proficient bilinguals translating abstract words. It would be interesting to manipulate word difficulty (use less frequent or abstract critical words) in the present study design and see if the results could be replicated.

\section{Conclusions}

My study has shown shorter translation latencies for L2-L1 direction as opposed to L1-L2 direction. The participants have performed more efficiently when providing translation equivalents in their L1. We have to bear in mind that the experimental study described here included only word translation as an experimental task and this cannot be fully generalisable to the actual interpreting task. However, translation of words (in context) is a subtask inherent in interpreting. This is why it seems that such findings could lend partial and indirect support to the approach to the directionality issue in interpreting favoured by Western scholars (such as Seleskovitch and Lederer 1989) and international organisations (such as the UN and the EU). 
According to this approach, interpreting should only be done into the interpreter's native language due to L1 advantage in production. Contrary to my predictions, the directionality effect (L2-L1 direction advantage) was found only in the group of bidirectional interpreters and not in the group of unidirectional interpreters. I expected that the extensive interpreting experience into the L1 only shared by unidirectional interpreters would be manifested in the asymmetry of the lexical links in their mental lexicon and lead to shorter L2-L1 translation latencies. Following similar reasoning, I expected no direction asymmetry in translation latencies by bidirectional interpreters who work equally often into their L1 and their L2. It turned out that the predominant directionality in their professional interpreting practice plays no or smaller role in shaping the strength of the lexical links than other factors. These factors include language use, exposure and immersion. Since my bidirectional interpreters live and work in an L1 environment, they manifested L2-L1 direction advantage. On the contrary, the unidirectional interpreters work in an L2 environment and live in an L3 environment. Thus, their L1 advantage may be attenuated. In general, the findings are in line with the assumption of the Revised Hierarchical Model regarding the dynamic nature of word-to-concept and word-to-word mappings in the bilingual lexicon.

My assumptions regarding context effects were confirmed by the study. The interpreters used the high context constraint to predict the sentence final word, which resulted in shorter translation latencies in highly constrained sentences as opposed to unconstrained sentences. Additionally, I found an interaction between context and direction in the data for bidirectional interpreters. It seemed that they were able to better predict L1 sentence endings than L2 sentence endings and this resulted in faster L1-L2 translation in semantically constrained sentences as opposed to faster L2-L1 translations in semantically unconstrained sentences. Unidirectional interpreters manifested no such modulation, which I explain by saying that their L2-L1 interpreting practice (which entails extensive analysis and parsing of their L2) offsets L1 comprehension advantage. It is worth mentioning here that using a word translation task in semantically constrained and unconstrained sentences proved a good method to test anticipation performed by conference interpreters. Anticipation is claimed to be an important part of conference interpretation (Seeber 2001; Chernov 2004). In Interpreting Studies literature, it has often been perceived and studied as a directly observable product: a translation equivalent for a given word uttered by the interpreter before the speaker utters that word. The present study design makes it possi- 
ble to study anticipation manifested as shorter translation latencies that reflect pre-activation of the translation equivalent. The present study has indeed shown that interpreters efficiently use semantic context to anticipate the following words, as I found a significant difference in translating words embedded in high context and low context constraint sentences.

In general, the study has demonstrated that conference interpreters are an interesting case of bilinguals who engage in a specific type of bilingual processing on a daily basis. Studies involving interpreters as participants can inform psycholinguistic models of the mental lexicon, while bilingual theories can be useful in researching the process of conference interpreting.

\section{REFERENCES}

AIIC. 2014. "Regulation governing admissions and language classification". Available at $<$ http://aiic.net/page/6726>. Last accessed 06 Aug 2015.

Altarriba, J., J.F. Kroll, A. Sholl and K. Rayner. 1996. "The influence of lexical and conceptual constraints on reading mixed-language sentences: Evidence from eye fixations and naming times". Memory and Cognition 24(4). 477-492.

Baayen, R.H., D.J. Davidson and D.M. Bates. 2008. "Mixed-effects modeling with crossed random effects for subjects and items". Journal of Memory and Language 59(4). 390-412.

Barr, D.J., R. Levy, C. Scheepers and H.J. Tily. 2013. "Random effects structure for confirmatory hypothesis testing: Keep it maximal". Journal of Memory and Language 68(3). 255-278.

Bartłomiejczyk, M. 2006. "Strategies of simultaneous interpreting and directionality". Interpreting 8(2). 149-174.

Bates, D. 2007. "Linear mixed model implementation in lme4". (Unpublished manuscript, University of Wisconsin-Madison.)

Chang, C. 2005. Directionality in Chinese/English simultaneous interpreting: Impact on performance and strategy use. ( $\mathrm{PhD}$ dissertation, University of Texas at Austin.)

Chernov, G.V. 1992. "Conference interpretation in the USSR: History, theory, new frontiers". Meta 37(1). 149-162.

Chernov, G.V. 2004. Inference and anticipation in simultaneous interpreting: $A$ probability-prediction model. Amsterdam: John Benjamins.

Chmiel, A. In preparation. "The influence of interpreter training on working memory and the bilingual mental lexicon".

Christoffels, I.K., A.M.B. de Groot and J. Kroll. 2006. "Memory and language skills in simultaneous interpreters: The role of expertise and language proficiency". Journal of Memory and Language 54(3). 324-345.

Christoffels, I.K., A.M.B. de Groot and L.J. Waldorp. 2003. "Basic skills in a complex task: A graphical model relating memory and lexical retrieval to 
simultaneous interpreting”. Bilingualism: Language and Cognition 6(3). 201211.

de Bot, K. 2000. "Simultaneous interpreting as language production". In: Englund Dimitrova, B. and K. Hyltenstam (eds.), Language processing and simultaneous interpreting: Interdisciplinary perspectives. Amsterdam: John Benjamins. 6588.

de Groot, A.M.B. and I.K. Christoffels. 2006. "Language control in bilinguals: Monolingual tasks and simultaneous interpreting". Bilingualism: Language and Cognition 9 (2). 189-201.

de Groot, A.M.B., L. Dannenburg and J.G. van Hell. 1994. "Forward and backward word translation by bilinguals". Journal of Memory and Language 33 (5). 600 629.

de Groot, A.M.B. and R. Poot. 1997. "Word translation at three levels of proficiency in a second language: The ubiquitous involvement of conceptual memory". Language Learning 47. 215-264.

Denissenko, J. 1989. “Communicative and interpretative linguistics". In: Gran, L. and J. Dodds (eds.), The theoretical and practical aspects of teaching conference interpretation. Udine: Campanotto. 155-158.

DG Interpretation. 2012. "The conference interpreter's language combination". Available at $<\mathrm{http} / /$ ec.europa.eu/dgs/scic/what-is-conference-interpreting/ language-combination/index_en.htm>. Last accessed 06 Aug 2015.

Donovan, C. 2002. "Survey of user expectations and needs". In: Teaching simultaneous interpretation into a 'B' language. EMCI Workshop proceedings. Paris: ESIT. 2-11.

Donovan, Clare. 2005. "Teaching simultaneous interpretation into B: A challenge for responsible interpreter training". Communication and Cognition. Monographies 38(1-2). 147-166.

Duyck, W. and M. Brysbaert. 2008. "Semantic access in number word translation: the role of crosslingual lexical similarity". Experimental Psychology 55(2). 102112.

Gile, D. 2005. "Directionality in conference interpreting: A cognitive view". Communication and Cognition. Monographies 38(1-2). 9-26.

Gile, D. 2015. "The contributions of cognitive psychology and psycholinguistics to conference interpreting. A critical analysis". In: Ferreira, A. and J. W. Schwieter (eds.), Psycholinguistic and congitive inquiries into translation and interpreting. Amsterdam: John Benjamins. 41-66.

Gran, L., and F. Fabbro. 1988. "The role of neuroscience in the teaching of interpretation". The Interpreters' Newsletter 1. 23-41.

Gumul, E. 2006. "Explicitation and directionality in simultaneous interpreting". Available at $<$ http://www.emcinterpreting.org/?q=system/files/Explicitation Directionality SI Gumul.pdf>. Last accessed 07 Aug 2015.

Heij, W.L., Hooglander, A., Kerling, R. and E. van der Velden. 1996. "Nonverbal context effects in forward and backward word translation: Evidence for concept mediation". Journal of Memory and Language 35(5). 648-665.

Jörg, U. 1997. "Bridging the gap: Verb anticipation in German-English simultaneous interpreting”. In: Snell-Hornby, M., Z. Jettmarová and K. Kaindl (eds.), Trans- 
lation as intercultural communication. Amsterdam: John Benjamins Publishing. 217-228.

Katschinka, L. 2002. "Survey on the conference interpreting profession in Central and Eastern Europe". <http://www.jtpunion.org/english/Conf_int_survey.htm>. Last accessed 15 Oct 2009.

Kroll, J.F. and E. Stewart. 1994. "Category interference in translation and picture naming - evidence for asymmetric connections between bilingual memory representations". Journal of Memory and Language 33(2). 149-174.

Kroll, J.F., J.G. van Hell, N. Tokowicz and D.W. Green. 2010. "The Revised Hierarchical Model: A critical review and assessment". Bilingualism: Language and Cognition 13(3). 373-381.

Kroll, J.F., E. Michael, N. Tokowicz and R. Dufour. 2002. "The development of lexical fluency in a second language". Second Language Research 18(2). 137171.

Kujałowicz, A., A. Chmiel, K. Rataj and M. Bartłomiejczyk. 2008. "The effect of conference interpreting training on bilingual word production". Paper presented at the 39th Poznań Linguistic Meeting (PLM2008), Gniezno, Poland.

Kurz, I. and B. Färber. 2003. "Anticipation in German-English simultaneous interpreting". Forum 1(2). 123-150.

Lim, H.-O. 2005. "Working into the B language: The condoned taboo?" Meta 50(4).

Linck, J.A., J.F. Kroll and G. Sunderman. 2009. "Losing access to the native language while immersed in a second language: Evidence for the role of inhibition in second-language learning". Psychological Science 20(12). 1507-1515.

Mead, P. 2005. "Directionality and fluency: an experimental study of pausing in consecutive interpretation into English and Italian". Communication and Cognition. Monographies 38(1-2). 127-146.

Morris, R.K. 2006. "Lexical processing and sentence context effects". In: Traxler, M. and M. Gernsbacher (eds.), Handbook of psycholinguistics. (2nd ed.) London: Elsevier. 337-402.

Nicodemus, B. and K. Emmorey. 2013. "Direction asymmetries in spoken and signed language interpreting". Bilingualism: Language and Cognition 16(3). 624-636.

Padilla, P., J.J. Cañas and F. Padilla. 1995. "Cognitive processes of memory in simultaneous interpretation". In: Tommola, J. (ed.), Topics in interpreting research. Turku: University of Turku, Centre for Translation and Interpreting. 6171.

Pavlović, N. 2007. "Directionality in translation and interpreting practice. Report on a questionnaire survey in Croatia". Forum 5(2). 79-99.

R Development Core Team. (2009). "R: A language and environment for statistical computing". Available at <http://www.R-project.org>. Last accessed 29 Oct 2015.

Rejšková, J. 2002. “Teaching experience of simultaneous into B”. In: Teaching simultaneous interpretation into a ' $B$ ' language. EMCI Workshop proceedings. Paris: ESIT. 30-34.

Riccardi, A. 1998. "Interpreting strategies and creativity". In: Beylard-Ozeroff, A., J. Králová and B. Moser-Mercer (eds.), Translators' strategies and creativity. Amsterdam: John Benjamins. 171-180. 
Schwartz, A.I. and J.F. Kroll. 2006. "Bilingual lexical activation in sentence context". Journal of Memory and Language 55(2). 197-212.

Seeber, K.G. 2001. "Intonation and anticipation in simultaneous interpreting". Cahiers de Linguistique Française 23. 61-97.

Seleskovitch, D. and M. Lederer. 1989. Pédagogie raisonnée de l'interprétation. Paris: Didier.

Seleskovitch, Danica. 1978. Interpreting for international conferences: Problems of language and communication. Washington: Pen \& Booth.

Seleskovitch, D. and M. Lederer. 1995. A systematic approach to teaching interpretation. Silver Spring: Registry of Interpreters for the Deaf.

Setton, R. 1999. Simultaneous interpretation: A cognitive-pragmatic analysis. Amsterdam: John Benjamins.

Sholl, A., A. Sankaranarayanan and J.F. Kroll. 1995. "Transfer between picture naming and translation: A test of asymmetries in bilingual memory". Psychological Science 6(1). 45-49.

Shreve, G.M. and B.J. Diamond. 1997. "Cognitive processes in translation and interpreting: Critical issues". In: Danks, J. (ed.), Cognitive processes in translation and interpreting. London: Sage. 233-251.

Sunderman, G. and J. F.Kroll. 2006. "First language activation during second language lexical processing: An investigation of lexical form, meaning, and grammatical class". Studies in Second Language Acquisition 28(3). 387-422.

Sunnari, M. 1996. "Comparison of expert and novice performance in simultaneous interpreting". In: Proceedings of the XIV World Congress of FIT. Melbourne. 993-1000.

Szabari, K. 2000. “Körkép a konferencia-tolmács szakmáról egy felmérés tükrében" [An overview of conference interpreting in the light of a survey]. Fordítástudomány 2(1). 71-87.

Szabari, K. 2002. "Interpreting into the B Language". In: Teaching simultaneous interpretation into a ' $B$ ' language. EMCI Workshop proceedings. Paris: ESIT. 12-19.

Titone, D., M. Libben, J. Mercier, V. Whitford and I. Pivneva. 2011. "Bilingual lexical access during L1 sentence reading: The effects of L2 knowledge, semantic constraint, and L1-L2 intermixing". Journal of Experimental Psychology: Learning, Memory and Cognition 37(6). 1412-1431.

Tommola, J. and M. Helevä. 1998. "Language direction and source text complexity: Effects on trainee performance in simultaneous interpreting". In: Bowker, L., M. Cronin, D. Kenny and J. Pearson (eds.), Unity in diversity. Current trends in translation studies. Manchester: St. Jerome. 177-186.

van Assche, E., D. Drieghe, W. Duyck, M. Welvaert and R.J. Hartsuiker. 2011. "The influence of semantic constraints on bilingual word recognition during sentence reading". Journal of Memory and Language 64(1). 88-107.

van Dam, H. 2001. "On the option between form-based and meaning-based interpreting: The effect of source text difficulty on lexical target text form in simultaneous interpreting". The Interpreters' Newsletter 11. 27-55. 
van Hell, J.G. 2005. "The influence of sentence context constraint on cognate effects in lexical decision and translation." In: Proceedings of the 4th International Symposium on Bilingualism. Somerville: Cascadilla Press. 2297-2309.

van Hell, J.G. and A.M. de Groot. 2008. "Sentence context modulates visual word recognition and translation in bilinguals". Acta Psychologica 128(3). 431-451.

\section{Address correspondence to:}

Agnieszka Chmiel

Faculty of English

Adam Mickiewicz University

Collegium Novum

al. Niepodległości 4

61-874 Poznań

Poland

magnes@wa.amu.edu.pl 